\title{
O espírito de Saussure: recepção e herança (a herança linguística saussuriana: Paris contra Genebra) ${ }^{1}$
}

Christian Puech

Universidade Paris III, Sorbonne Nouvelle

Se no subtítulo tomo a liberdade de voltar abertamente ao título que nos foi proposto para esta mesa-redonda, é porque ele mistura, com efeito, de maneira estreita, de um lado, localizações espaciais (dois nomes de cidades europeias), de outro, certo tipo de implicação no tempo: aquele que traz consigo o termo "herança".

Mas o que de fato e exatamente traz consigo o termo herança? Que tem ele a ver com a linguística saussuriana? Até que ponto? Como distribuir aqui a série de semas mais ou menos virtuais e sempre muito "pesados" que lhe são associados: os legados, a dívida, a legitimação por ascendência mais ou menos direta, mas também o limite, por que não o fardo ou o obstáculo...? Por outro lado, o título e o texto de apresentação instalam uma oposição "Paris contra Genebra" que, modulada por uma interrogação, é submetida a nossa apreciação e a nossa faculdade de reagir a uma pequena provocação (o leitor pode imaginar uma guerra franco-suíça declarada por Saussure ou em seu nome?) capaz de fazer girar, em suma, uma mesa-redonda.

Em relação a esse último ponto - fazer girar as mesas - sabe-se que a figura de Saussure é particularmente apropriada e, por associação mais ou menos livre, pode-se lembrar aqui ao menos do título de um artigo de G. Lepschy sobre o caso H. Smith, espírita glossolálica, e sobre a parte que F. de Saussure quis muito tomar no caso: "Saussure e os espíritos". Mas não é certo que a participação de Saussure em uma ciência dos espíritos no século XX se resuma a esse episódio bem conhecido: “o espírito de Saussure”, aquele que, hoje, buscamos cada vez mais opor à "letra de Saussure", percorre, com efeito, ao longo de quase um século da linguística contemporânea, toda a Europa (de Roma a Copenhague, de

\footnotetext{
1 Texto publicado em Modèles linguistiques, t. XX, fasc. 1, P.U.L., 2000. Tradução de Marcio Alexandre Cruz.

2 Lepschy, G. C. (1974).
} 
Genebra, Moscou e Praga a Paris), e muitos continentes. Uma recensão verdadeiramente exaustiva das traduções do $C L G$, das edições e reedições críticas, dos prefácios e introduções... traçaria por si só, sem dúvida, uma geografia dos lugares "assombrados", ao mesmo tempo que uma história muito pouco linear e um tanto acidentada da linguística... refratada pelo prisma de recepção da famosa obra.

\section{História e geografia saussurianas}

A bem da verdade, a ideia de uma "oposição" Paris/Genebra não é uma ideia nova. Ela percorre já há muito tempo a historiografia/geografia da formação do pensamento de Saussure, procurando determinar o momento preciso e o lugar geométrico exato da precipitação das ideias contidas no Curso.

Essa topologia tem seus lugares "escondidos": para mostrar que Paris é o centro de gravidade do pensamento saussuriano, é preciso, por exemplo admitir que Leipzig e Berlim não têm a importância que se lhe atribui muito frequentemente e também não acreditar na palavra de Saussure quando ele afirma, por exemplo, no Curso, que um dos limiares da modernidade linguística, um dos limiares principais para além do qual ele próprio pretende se colocar, foi alcançado pelos neogramáticos: “Graças a eles, não se viu mais na língua um organismo que se desenvolve por si mesmo, mas um produto do espírito dos grupos linguísticos (SAUSSURE, 1975, p. 19).

H. Aarsleff (1981, p. 115-133) procurou, há muito tempo, essa gênese que insistia no caráter ilusório da reconstrução saussuriana e na importância não confessada da Escola de Paris, onde Saussure teria sido colocado em contato com a "nova filosofia": seu antiespiritualismo ao mesmo tempo empirista (os fatos) e racionalista (poder organizador da vontade humana, contra o desabrochar cego das formas vivas), sob a influência de um Taine em filosofia, de um Durkheim em Sociologia ${ }^{3}$, de um Bréal em linguística. É somente nessa condição que se poderia concluir com H. Aarsleff que "Saussure não chega de Leipzig a Berlim já com as ideias que engendrarão o CLG na cabeça [ao passo que] ele não deixa Paris sem elas".

\footnotetext{
3 Cf. igualmente sobre esse ponto W. Doroszewski que, já em 1933, vê no conceito saussuriano de língua uma instituição, uma "representação coletiva exterior ao indivíduo" e "coercitiva" à la Durkheim e no conceito de "fala" uma realidade sociolinguística imitativa que deve tudo a G. Tarde.
} 
A importância de Genebra se encontraria, então, por consequência, relativizada, Paris tornando-se, em suma, capital da Suíça (romanda).

Mas essa tipologia não tem apenas sua geografia aleatória, ela tem igualmente seus "momentos cruciais", suas "circunstâncias". Ela procura, seja no curto prazo da biografia saussuriana, seja no longo prazo da história das ideias linguísticas, seja entre as duas, na perspectiva histórico-biográfica, medir a novidade de Saussure contextualizando (ampla ou estreitamente) seus aportes mais decisivos, isto é, determinando-os, nomeando-os e avaliando-os. Esse tipo de abordagem, perfeitamente compatível com o tipo precedente, recobre uma grande parte da literatura saussuriana (da "bibliografia saussuriana", para retomar o título da rubrica das recensões regulares de R. Engler nos Cabiers Ferdinand de Saussure): assim, não faremos o impossível inventário dessa literatura. Mas desse ponto de vista, tudo é realmente uma questão de focalização (que aspecto do pensamento de Saussure?), de periodização (qual extensão?), de ponto de vista (história conceitual?, História das ideias?, Metodologias? Sociologia das instituições científicas?...).

Dois exemplos apenas, tomados de duas extremidades do "espectro" (sem jogo de palavras) sobre o qual "o espírito de Saussure" percorre certos aspectos de nossa modernidade. J. Derrida, em 1968, de um ponto de vista certamente "exterior" à linguística e a sua história (mas até que ponto?), propõe sob o título "O círculo linguístico de Genebra" um enraizamento geográfico da metafísica do signo que é ao mesmo tempo uma "prisão domiciliar" do pensamento do signo (Genebra) e sua "intimação" para comparecer ao tribunal da história pela coincidência dos estilos de Rousseau e de Saussure na tradição metafísica do "logocentrismo". O efeito é surpreendente: a história e a geografia estão ironicamente juntas em detrimento das mediações históricas, sem dúvida, mas em benefício do "historial" como estrutura não de eventos (événementielle), quase transcendental. Saussure continua então alguma coisa que ele ajuda também a subverter, mas com novos argumentos, em uma nova sintaxe.

$\mathrm{Na}$ outra extremidade do espectro, aquela de uma sociologia da ciência com inspiração em Merton, O. Amsterdamska (1987) coloca, ao contrário, a questão da instalação, encaminhamento de uma filiação e de uma memória saussuriana em termos de continuidade conceitual e institucional. Mas segundo a autora, se "a escola saussuriana" (cuja existência é indubitável a seus olhos) constituiu-se em Genebra e não em Leipzig, que ignora Saussure, ou em Paris, que o reconhece, seria porque apenas a Universidade 
Helvética da época o permitia. A universidade alemã estando "trancada" pelos neogramáticos; a universidade francesa estando ocupada por personalidades científicas como a de Bréal e a, tentacular, de Meillet, só restava a Saussure Genebra para afirmar a preeminência e a legitimidade da linguística sincrônica. Geografia e história se ligam aqui também como determinação empírica da teoria sobre os eixos do espaço e do tempo.

Poderíamos, certamente, multiplicar os exemplos dessas "indisposições" de um fragmento de história da linguística que faria valer os mesmos lugares e os mesmos momentos com profundas diferenças de acentuação e de valorização, ou colocariam em evidência outros lugares e outros momentos da formação do pensamento de Saussure. Podemos, por exemplo, uma vez admitida a importância de Paris nessa formação, praticar uma micro-história, que é também uma micro-topografia: o tipo de conceito de "linguística geral" que conhecerá seu desdobramento mais completo apenas em Genebra, não teria ele dependido ao menos em parte dos lugares respectivos que ocupavam na École Pratique, em um mesmo espaço, portanto, as personalidades de Meillet e Saussure e da distancia relativa que os ligava a esse mesmo espaço?

É um pouco a questão que K. Koerner coloca em 1973, depois novamente em 1988, quando ele interroga em termos de "influência" a origem da célebre definição da língua como "sistema em que tudo se relaciona", fazendo da relação mestre/disciplina uma relação potencialmente biunívoca e, por aí mesmo, da distância Paris/Paris o padrão de medida da distância Paris/Genebra.

Se privilegiarmos agora mais a problemática da "reconstrução" das teorias linguísticas independentemente de qualquer consideração sobre a "influência", poderemos ver então no passado das teorias da sinonímia a fonte principal de inspiração da teoria saussuriana do valor (AUROUX, 1985), para além de todo enraizamento histórico-geográfico próximo. Mas não se trataria aí de outra maneira de medir uma distância relativa no espaço e no tempo?

\section{O antes e o depois: a herança saussuriana}

Mas há também outra maneira de considerar a relação Paris/Genebra. Trata-se desta vez de se levar em conta não apenas o antes do Curso, mas também as diferentes modalidades 
segundo as quais se operam retrospectivamente suas diversas reapropriações, em uma palavra, o depois.

Desse ponto de vista, se Genebra parece realmente ser o lugar das origens (estabelecimento do texto por [ou de] Bally e Sechehaye, retomada filológico-crítica extremamente minuciosa de R. Godel e R. Engler, comentário com uma visada "literal” de R. Amacker, de Wunderli, de C. Mejía, de M. C. Capt-Artaud...), Paris seria antes o lugar das reinterpretações projetivas. Por esse termo, designo o conjunto (que não constitui de modo algum uma totalidade harmoniosa e finita) daquilo que temos boas razões para chamar de "metabolizações” do Curso de Linguística Geral. Estas podem ser linguísticas (por exemplo R. L. Wagner, G. Gougenheim, G. Guillaume, A. Martinet, E. Benveniste a títulos diversos), paralinguísticas ou perilinguísticas (A. J. Greimas e R. Barthes, Prieto, por exemplo) ou não-linguísticas (mesmo se a linguística está implicada). É em Saussure, por exemplo, que Merleau-Ponty procurava no fim dos anos 1950 certa renovação da filosofia da história à luz das célebres dicotomias saussurianas diacronia/sincronia, língua/fala. É em Saussure ainda que Derrida confirma o motivo da "différance", em uma aproximação conflituosa com a "differenz" heideggeriana; é no CLG que Foucault vê em 1966, ao lado dos primeiros desenvolvimentos de Chomsky, o ressurgimento de uma "teoria geral da mente humana" cujo projeto remontaria pelo menos a Port-Royal; é evidentemente ao conceito de signo que remete, por um lado ao menos, a tematização lacaniana do "significante"... etc.

Vê-se claramente que essa ideia de divisão internacional das tarefas traz consigo ao mesmo tempo a evidência e os limites de toda alegação de um "fato" empírico. Sem dúvida, é realmente em Genebra que os grandes trabalhos de filologia são levados a cabo com afinco e paciência, como lembrávamos há pouco, obrigando os especuladores parisienses a uma higiene intelectual (vista de Paris, Genebra é ainda a capital mundial da higiene...) infinitamente salutar e frequentemente corrosiva, que eles estão longe de levar em conta. Que valem, com efeito, as especulações mais ousadas, se elas são feitas a partir de um material faltoso ou lacunar ou "apócrifo", como se diz às vezes?

Mas ao mesmo tempo o corpus saussuriano é perturbado por todos os paradoxos da autenticidade. Com efeito, o que prova a autenticidade dos textos manuscritos e das notas, se é a "inautêntica" versão do Curso que adquiriu desde sempre uma dimensão autêntica histórica? Se o Curso apenas se tornou um objeto histórico depois que foi investido de 
valores culturais os mais variados, objeto de leituras menos consensuais do que demarcativas, e isto sob a forma que the quiseram dar Bally e Sechehaye, depois, em Paris particularmente, o trabalho de T. de Mauro? Essas questões, pergunto, não convidariam a uma reflexão sobre o status cultural de um texto como o Curso, não para opor status cultural e status científico, mas antes para pleitear em favor de sua historicidade radical, indissociável? Que o $C L G$ possua uma história, isso não se deve apenas aos avatares filológicos dos materiais a partir dos quais o temos como "instituído", isso não se deve apenas à sua gênese, mas aos modos de reapropriações, referências mais ou menos operacionais, simbólicas ou estratégicas, de um trabalho seletivo de memória, em uma palavra à sua "produtividade" particularmente fecunda. Certamente Saussure não é aquele que os "grandes nomes parisienses" nos fizeram crer que ele fosse. No entanto, não se pode taxar estes últimos de duplicidade. Nenhum outro Saussure esteve disponível no mercado das ideias durante tanto tempo, e a "invenção" do Curso não se deve unicamente a Bally e Sechehaye, mas a todos os leitores do texto que eles colocaram à disposição e fizeram circular, conferindo-lhe, desse modo, o status por assim dizer de objeto semiológico...

É nesse ponto que a problemática da localização geográfica do "verdadeiro" Saussure encontra seu limite e obriga antes a precisar que tipo de determinação temporal implica com ela a noção de "herança". São várias as razões para tal. Todas, do meu ponto de vista, relativizam a oposição Genebra/Paris de que partimos e devem conduzir antes a um novo exame do regime historiográfico complexo que comanda o "destino" do texto saussuriano.

A) Primeiramente, poderíamos pensar que as tradições gramaticais sempre se instauraram no longo prazo de processos ininterruptos de transmissão, a partir de textos canônicos (às vezes explicitamente citados, outras vezes não). É nesse sentido que se pode ter toda a medida da "herança" deixada por Donato ao longo de vários séculos de tradição gramatical no Ocidente. É fácil mostrar que o CLG não possui esse status. De um lado, não temos o mesmo distanciamento temporal, o período que nos separa do ponto de origem é demasiado curto. Depois, a herança gramatical se transmite somente pelas práticas pedagógicas instituídas de longa duração, do que o trabalho de Saussure não participa ou, ao menos, não da mesma maneira. Certamente houve um impacto da linguística saussuriana na disciplinarização escolar/universitária da linguística, e o CLG é, realmente, desde sua origem inacessível um curso. Mas a ação de reformulação dos estudos gramaticais, levada a cabo em parte apenas sob a égide da linguística saussuriana nos anos 1960 na 
França, operou-se precisamente sob o signo de uma recusa ou de uma alteração (bem sucedida ou não) da tradição...

B) Depois, se a difusão do Curso acompanhou de perto a emergência de uma "consciência disciplinar" da linguística desde o primeiro congresso internacional de linguistas em Haia, pelo menos em 1928, é sob o signo de uma internacionalização/unificação das práticas de pesquisa, a um nível principial demasiado geral, que é muito difícil fazer retrospectivamente a partilha entre herdeiros legítimos e ilegítimos, fieis e infiéis, mais ligados à letra ou mais ligados ao espírito ( $f f$. Infra). A hipótese mais verossímil é que o Curso forneceu retrospectivamente uma referência desterritorializada e polêmica a projetos muitas vezes concorrentes e tardiamente percebidos sob o título único do "estruturalismo" (aquilo que chamamos de a linguística dos "círculos"). Essa etiqueta tem tudo para ser, em grande parte, enganadora, ela é parte integrante, no entanto, da história do CLG. De certa maneira, não houve jamais saussurismo no sentido de Praga, Copenhague, Paris sem uma saussurologia mínima: exegese valorizadora, inventário discriminante do patrimônio deixado, ênfase de certos aspectos em detrimento de outros...

C) O que nos conduz ao terceiro ponto: a pluralização das figuras de Saussure. É ela que se convoca mais ou menos implicitamente hoje quando se opõe Genebra a Paris: o Saussure da indispensável "saussurologia" genebrina (para ser breve) coincidiria apenas em parte por vezes de modo algum - com a figura do "heroi teórico" parisiense.

Vale a pena aqui observar que a própria ideia de um Saussure plural já possui sua história. Ela surgiu nos anos $1970 \mathrm{com}$ a imagem dos dois Saussure, o do Curso e o dos Anagramas, e está estreitamente ligada à filologia saussuriana de J. Starobinski, alternada pelos paragramas de J. Kristeva, difundindo amplamente o retrato em díptico do Saussure diurno e noturno. Pode-se perguntar, contudo, se essa proliferação das figuras de Saussure não teria começado muito antes, mesmo se com valorizações diferentes, e mesmo, às vezes, opostas. Quando estudamos as resenhas do CLG (cf. Chiss 1978 apud Normand et al. 1978) que acolheram as primeiras edições, percebemos que, sem dúvida, sempre se opôs Saussure ao próprio Saussure e consequentemente não apenas Genebra a Paris ou Paris e Genebra a Leipzig, mas Genebra a Genebra. Poderíamos sustentar, mais ou menos explicitamente, que o Saussure do Curso era o Saussure noturno (o teórico especulativo) ao qual poderíamos opor o Saussure cristalino, positivo e genial do Mémoire ( $c f$. a resenha de $\mathrm{H}$. Schuchardt in NORMAND et al., 1978, p. 174-181), como mais tarde e numa perspectiva inversa, oporemos o Saussure do Curso ao dos Anagramas, ao da correspondência com Flournoy ou, mais recentemente, ao das Lendas germânicas... A proliferação das figuras de 
Saussure passa pela interpretação sempre retrospectiva e/ou projetiva de um texto certamente mutilado por sua primeira edição. Pode-se, contudo, duvidar que uma edição completa possa retirar algumas das características mais marcantes que, sem dúvida, fizeram sua produtividade e seu destino lábil.

D) Dentre essas características, parece-me que se pode, em quarto lugar, isolar aquelas que se prestam mais a esse jogo interpretativo/projetivo, o que melhor produz historicidade, independentemente da vontade e das várias “intenções” do autor.

a) Trata-se, antes de tudo, de um estilo epistemológico que se poderia qualificar de "minimalista". Simplificando, poderíamos sugerir a ideia de que as principais interpretações do CLG se apoiaram no jogo das dicotomias mínimas que ele instaura (na versão Bally/ Sechehaye) seja para acrescentar um termo a seu "dualismo" (como quando G. Guillaume faz valer os direitos do "discurso" ao lado dos direitos da "língua" ou da "fala", seja para restituir, de um modo ou de outro, a dignidade teórica da parte supostamente excluída desses dualismos (a diacronia ao lado da sincronia para Jakobson e, sobretudo, Troubetzskoi, ou Martinet, a fala para Benveniste e já para Bally), seja para radicalizá-las como parece fazer Hjelmslev com a distinção forma/substância. Em todos esses casos aqui referidos de modo um tanto disperso e que se poderia facilmente completar, o Curso aparece não como um manual doutrinal, mas como uma reflexão de princípios que pede para ser completada porque parece que ela nunca oferece seja lá o que for com uma mão, sem que se retire, com a outra, uma contrapartida negativa. Esse estilo minimalista é um estilo frustrante que, ao que parece, só pode prometer, desapontando. É difícil não aproximá-lo do estilo de um contemporâneo seu, menos visível, V. Henry, que publicou, ele também, com seu próprio nome, um tratado de linguística geral em 1896 por meio de três antinomias e também não se perguntar sobre o que, no final do século XIX, levava a esse estilo "crítico" na reflexão ao mesmo tempo geral e técnica sobre a linguagem, cujo principal exemplo é Saussure, mas não o único.

b) O Curso de Bally e Sechehaye já deixa perceber o seu lugar numa situação de crise dos saberes, crise que a posteridade tenderá a esquecer, do mesmo modo que ela tenderá a esquecer a dimensão crítica/reflexiva do projeto semiológico saussuriano. Sabe-se que a novidade desse projeto é muito pouco percebida aos olhos dos contemporâneos, e A. Meillet nem sequer chega a fazer menção a tal projeto em sua resenha do Curso. Por outro lado, quando Saussure se torna, retrospectivamente, um marco na memória das ciências 
humanas em sua versão estruturalista, a semiologia passa então a ser um paradigma unificador e transdisciplinar. Esquece-se, então, que no Curso, a semiologia aparece apenas como um eixo reformador da psicologia e da sociologia e, de forma mais geral, de toda disciplina desde que ela se ocupe "do valor", e não como um projeto positivista de totalização de disciplinas que entram, definitivamente, na via real da ciência. T. de Mauro mostrou as hesitações (dos editores? De Saussure?) relativas aos termos "psíquico" e "psicologia" no Curso. Quanto à afirmação do "caráter social (interno) dos fatos linguísticos", ela se inscreve (DURKHEIM, TARDE, entre outros) nas principiais discussões da sociologia em vias de se constituir. Aqui também as condições de cientificidade são, em Saussure, essencialmente restritivas, ao mesmo tempo animadoras e frustrantes.

c) Enfim, seria preciso poder mensurar de modo sistemático os efeitos de reformulação (e de reformulação de reformulações) dos quais o Curso foi objeto desde sua publicação e de todas as partes. Constituiu-se aí um filtro de leitura privilegiando claramente as teses saussurianas em detrimento dos procedimentos, impedindo que se percebesse a complexidade histórica da recepção do CLG em trabalhos como os de Ch. Bally, G. Gougenheim ou G. Guillaume (entre outros), ao mesmo tempo continuadores de Saussure e, no entanto, inassimiláveis ao estruturalismo... ao qual o próprio Saussure é, sem dúvida alguma, estranho. Desde 1917, em sua resenha do Curso (“Os problemas da língua à luz de uma teoria nova"), A. Sechehaye inaugura um tipo de referência a Saussure: ele "reduz", segundo seus próprios termos, a doutrina de Saussure a certo número de "teses" (língua/fala, arbitrário, ponto de vista semiológico, valor...), mostrando ao mesmo tempo seu caráter inaugural... e insuficiente.

Minimalismo epistemológico, crise dos saberes, constituição de uma vulgata que vai muito além do trabalho de edição de Bally e Sechehaye são, de fato, características do corpus saussuriano que contribuíram amplamente para fazer dele uma ferramenta histórica de “disciplinarização" dos saberes linguísticos para o século XX. É essa ferramenta de disciplinarização que se retoma continuamente a partir dos anos 1930 para discutir suas teses, medir seu aporte propriamente cognitivo, sem dúvida, mas também para repetir versões cristalizadas, determinar as diferenças ou continuar em uma dinâmica incessante de "retomada". 
E) É por isso que, em quinto lugar, uma vez concluída uma parte do trabalho de “reconstrução" do corpus saussuriano (GODEL, ENGLER, KOMATSU, BOUQUET...), deveria ser possível medir seus efeitos. Um deles me parece paradoxal: quanto mais o "verdadeiro rosto" de Saussure se delineia, mais as escolhas de Bally e Sechehaye aparecem pelo que elas são: escolhas cujas motivações devem ser interrogadas de maneira mais sofisticada que o modo como se faz em geral, isto é, a partir da alternativa traição/fidelidade ou de outras considerações mais psicológicas do que históricas. Sabe-se que Bally e Sechehaye desenvolveram uma conceitualidade linguística que não é, de modo algum, um acréscimo ou uma continuação da obra (conhecida) de Saussure. Como então explicar que as "omissões" dos dois editores tenham relação particularmente com os domínios e os tipos de abordagem que eles mais frequentemente privilegiaram em seus trabalhos: a psicologia e a linguística da fala no caso de Sechehaye, desde Programa e métodos da linguística teórica (1908), obra dedicada a Saussure, e a linguística da fala e a "estilística", no caso de C. Bally? Este último procurou constituir a linguística da fala não completando e sistematizando o CLG, mas deslocando categoricamente o campo conceitual de Saussure. A estilística, inicialmente considerada por seu autor como uma "província" anexada ao domínio da língua saussuriana, aparece mais tarde como uma etapa que vai da linguística psicológica a uma verdadeira teoria linguística da enunciação.

Aliás, segundo qual necessidade Bally e Sechehaye deveriam eles ser linguistas saussurianos? Os editores do Curso não se formaram na escola saussuriana, mas na Alemanha, como o próprio Saussure (WUNDERLI, 1982). Somente por teleologia retrospectiva e, sem dúvida, por hipóstase dos princípios saussurianos herdados através do prisma de suas reinterpretações ulteriores, é que se pode esquecer o fundo dos debates do final do século XIX sobre o qual se erguem as "decisões teóricas" de Saussure: a onipresença da categoria plural de "falares", a importância redescoberta, em particular com a semântica de Bréal, da noção de "sujeito falante", os esboços múltiplos de pragmáticas (NERLICH, 1986) e de teorias dos atos de linguagem... Sem dúvida, o estudo sistemático das fontes confirma ao mesmo tempo que as "decisões" saussurianas do modo como elas aparecem no Curso redigido correspondem mais estreitamente com essa constelação de problemas das teorias 
da linguagem do que deixam crer as reinterpretações tardias e as epistemologias corretivas (Saussure não viu que...) ulteriores ${ }^{4}$.

F) Enfim, sabe-se que toda herança, todo exercício de um direito de sucessão, começa por um inventário explícito e exaustivo dos bens transmitidos; e está claro que a filologia saussuriana praticada em Genebra tem a ver com esse inventário. No entanto, parece-me que esse inventário indispensável porque ele sucede - e de longe - e não precede a difusão ampla do Curso, coloca dois problemas. De um lado, o da existência de uma herança implícita: Saussure teria transmitido mesmo aquilo que ele não transmitiu. De outro, o de uma herança tão geral que esta se encontra como "desmaterializada". Nos dois casos, novamente é o espírito de Saussure que bate na porta, e com mais força.

- No primeiro caso, trata-se da forte tentação de fazer do "verdadeiro" Saussure o "programador" de uma série de domínios da linguística moderna: aqueles que, precisamente, acreditaram somente poder se instituir legitimamente contra o programa saussuriano. Por exemplo, tenta-se mostrar que o conceito de "valor in praesentia" que se encontra desenvolvido nas fontes (e que é negligenciado no Curso) tem valor de programa:

Será que se pode dizer, diante de sua teoria sintagmática do valor, que por sua não-elaboração da noção de "fala" (ou de "discurso"), Saussure deixou de colocar, em seu programa, os conceitos epistemológicos próprios para permitir teorias da competência sintática, da pragmática linguística ou da análise do discurso? É justamente o contrário: seu conceito de "valor in praesentia" delineia o programa dessas linguísticas. Ainda, se outros - sejam eles sintaticistas, semanticistas ou pragmáticos - tematizaram conceitos epistemológicos ligados a esse valor in praesentia que não aparecem no Curso e que aparecem apenas de forma esparsa nos textos originais, seria injusto que eles demonstrassem insatisfação e reivindicassem aqui uma ruptura com seu programa epistemológico: é fácil mostrar que a linguística que eles praticam está, ao contrário, essencialmente edificada sobre esse programa (BOUQUET, 1997, p. 344-345).

Mas que vale então a noção de "epistemologia programática"? A noção de "programa"? Ela não remeteria aqui a uma forma moderna e pseudocientífica da predestinação? Mesmo se - é igualmente o nosso caso - atribuímos à noção de "influência" apenas um valor historiográfico pouco relevante em função de seu teleologismo (há no influenciado apenas o que se encontrava no "influente"), a ideia de tal "programa" agindo à distância e sem suporte não conduziria a uma desistoricização não menos radical? Ela não conduziria a uma heroicização renovada do pensador, lá onde o trabalho crítico deveria ter feito com

\footnotetext{
${ }^{4}$ Cf. por exemplo, R. Simone (1995) que mostra muito bem e essencialmente a partir do Curso redigido por Bally/Sechehaye, que a questão do lugar do sujeito falante está onipresente, quando se trata, para Saussure, de examinar a mudança linguística, as relações associativas, a arbitrariedade relativa e a analogia.
} 
que saíssemos do legendário ou, se preferimos, da legenda, isto é, daquilo que "deve ser lido".

- No segundo caso, é a própria questão da continuidade do saussurismo em Genebra que está em xeque. Sabe-se - e isso pelos próprios genebrinos - que esse topos de fato crucial permanece problemático desde Sechehaye (1927), até O. Amsterdamska (1987), passando entre outros - por Sechehaye (1940), H. Frei (1945), R. Godel (1961), R. Amacker (1976), Wunderli (1982). Seria a filiação institucional à cadeira de linguística geral de Saussure a Prieto suficiente para uma continuidade conceitual realmente operatória? Como medir esta última? Em 1961, R. Godel defende a ideia de uma Escola saussuriana de linguística própria à Genebra. Esse exercício necessita de uma advertência prévia, que vai além das simples precauções retóricas: "Para os linguistas saussurianos, os princípios estabelecidos pelo $C L G$ não são dogmas [...], eles são, segundo uma expressão do próprio Saussure, "pontos de vista sobre a linguagem"'. Esse relativismo de "ponto de vista" conduz à definição de uma espécie de saussurismo mínimo em cinco pontos fundamentais, núcleo duro da herança, em suma:

- a primazia da língua sobre a fala;

- a distinção rigorosa entre diacronia e sincronia;

- a conceituação da língua/sistema e instituição;

- a natureza dupla do signo;

- a arbitrariedade do signo e sua motivação por combinação sintagmática.

Se esses cinco pontos definem o mínimo da herança, eles também definem tarefas e, uma vez mais, um programa: desenvolver "princípios" apenas esboçados pelo Curso, sentir sua solidez colocando-os à prova da análise de outros sistemas, compará-los sobretudo com outros sistemas explicativos apoiando-se na saussurologia científica (edição crítica de R. Engler).

Ora, são esses cinco artigos de fé e seus adendos os artigos da carta fundadora de uma "Escola"? Não poderíamos legitimamente pensar que muitos projetos, localizados de modo diverso e assumindo ou não uma inscrição em Saussure, poderiam reivindicar esse programa? Melhor dizendo, aqueles que não se subscrevem à letra não poderiam, mesmo 
assim, se inscrever em tal projeto, uma vez que esses princípios forneceram, de fato, à posteridade saussuriana, o quadro a partir do qual revisões e críticas darão à disciplina a fisionomia que Saussure (e isso segundo seus próprios herdeiros) não poderia dar imediatamente, ele que teria fornecido, contudo, o melhor esboço? Desse ponto de vista, se a linguística saussuriana é a linguística da "Escola de Genebra", Genebra não seria então a capital, senão do mundo, ao menos, do mundo da linguística? Seja como for, o procedimento de Godel indica, mesmo se à revelia, uma das vias desejáveis da historiografia da linguística a partir de Saussure: que é uma escola? Uma escola Linguística? Que relação há em linguística entre teorização(ões), enraizamento nacional e linguístico com a idade da ciência, no momento da internacionalização das normas que presidem à pesquisa?

\section{Recepção e herança}

Ao final deste rápido percurso (para desenvolvimentos mais amplos, $c f$. CHISS e PUECH, 1987, 1997, 1999) o leitor terá compreendido que ele não visa em nada a desvalorizar o trabalho com as fontes, mas, pelo contrário, a incluí-lo em seu lugar no continente do saussurismo procurando ver em que ele pode desestabilizar as representações convenientes e repisadas. Talvez seja o momento, agora, de enumerar algumas dificuldades que apresenta, do nosso ponto de vista, a historiografia saussuriana.

- A primeira se deve, sem dúvida, aos anacronismos dos diferentes avatares da recepção de Saussure. O Saussure ao qual fazem referência as teses dos anos 1930 (em Haia ou Praga principalmente, depois Copenhague igualmente) é um Saussure já metabolizado em preocupações que não são mais exatamente aquelas da gênese do Curso e que possuem sua trajetória própria no universo dos eslavistas (SÉRIOT, 1999). O estruturalismo linguístico é já outra história, à procura de uma legitimidade pelas origens, que experimenta a necessidade de um marco de memória disciplinar para se instalar, conquistar seu lugar, ganhar outros novos, afirmar sua preeminência no centro a partir da periferia. O longo diálogo de Jakobson com Saussure ao longo de toda a sua carreira não diz outra coisa: Saussure é um começo imprescindível, mas apenas um começo, que será preciso retificar, e mesmo recomeçar. Troubetzkoi será ainda mais radical nessa via... 
Com o estruturalismo generalizado do pós-guerra, esse modo de referência a Saussure não faz senão aumentar e se radicalizar: o Curso desempenha então seu papel de referência absoluta através de uma série indefinida de mediações, de leituras de leituras, de prismas disciplinares cujos interesses de conhecimento são infinitamente diversos: Levi-Strauss lê Saussure através de Jakobson; Merleau-Ponty, através de G. Guillaume e Levi-Strauss, depois Martinet; Lacan através de Merleau-Ponty e Jakobson; Derrida através de Hjelmslev, etc.

Contrastando com essas leituras, a leitura de certas resenhas do Curso (Bloomfield, Meillet, Vendryès, Sechehaye, Schuchardt...) mostra a que ponto a recepção "imediata" foi subordinada a problemáticas (a de uma linguística social, de uma psicolinguística, de uma linguística histórica, a da mudança linguística, da sintaxe...) que resultam todas elas no modo de definir a linguística geral, e que conduzem frequentemente a lamentar seja a ausência de considerações sociológicas mais evidentes (Meillet, Vendryès ao seu modo), seja "abstração transcendente" (A. Sechehaye), seja o historiador comparatista de antes $\left(\right.$ Schuchardt $\left.{ }^{5}\right) \ldots$ em todos os casos a diminuir a novidade do Curso sobre a atualidade e o passado imediato de um campo de batalha.

- A segunda dificuldade reside na tentação, em parte legítima, é verdade, de reter do trabalho dos editores apenas a operação subtrativa de triagem nos materiais dos quais eles dispunham, ou as lacunas de sua informação. O conhecimento aprofundado das fontes não permitiria hoje ver também a contrapartida positiva dessas escolhas discriminantes e dessas ignorâncias em toda sua positividade? Em particular, Bally e Sechehaye ao menos tiveram o cuidado de reter nos materiais escolhidos aquilo que concerne ao horizonte de retrospecção do projeto de Saussure (na "visão geral da história da linguística"), sua relação com a definição do objeto, do método e da teoria do objeto, sem esquecer - mesmo se eles o fazem de maneira demasiado redutora - o horizonte de projeção (a semiologia); resumindo, tudo o que constitui uma disciplina como cristalização de problemas históricos, conceituais e culturais.

\footnotetext{
5 "Saussure chama a atenção como criador de sistemas, termo que deve ser considerado positivamente, do mesmo modo que "não sistemático", negativamente. Contudo, há sistemas que já estão inscritos nas coisas, pedindo apenas para serem descobertos e sistemas que nós criamos para aplicá-los às coisas. À primeira categoria, pertence, no que diz respeito a Saussure, o "sistema originário das vogais nas línguas indo-europeias", contido na dissertação de 1878; à segunda categoria, pertence o sistema de linguística geral que nos é hoje proposto postumamente. Sistemas desse tipo possuem apenas um valor provisório e condicional..." (SCHUCHARDT apud Normand et al. 1978, p. 174).
} 
Sem dúvida não há aí a unidade de uma “doutrina" linguística cujo conteúdo seria transmissível por acúmulo e capitalização (a via comum de constituição das heranças...) sem perda nem resto, nem tampouco, sem dúvida, um "programa" apenas à espera de sua realização, mas há certamente, por outro lado, uma matriz disciplinar que poderia ser reinvestida, transformada, estendida, contestada. O estruturalismo lhe teria dado forma e expressão por um momento. E se ela aparece hoje pelo que ela é, talvez seja porque ela está em vias de se desfazer sob nossos olhos.

- É por isso que, enfim, seria útil, sem dúvida - mas ainda é possível? Terceira dificuldade começar por distinguir no antes do Curso aquilo que diz respeito a uma recepção propriamente dita, que se integra, portanto, num "horizonte de espera" balizado por conceitos operatórios retomados, avaliados, ignorados e/ou criticados e aquilo que diz respeito à "herança" propriamente dita, isto é, a essa valorização retrospectiva de uma origem que nos apresenta o passado, talvez tardiamente, sob a figura paradoxal de nosso futuro antecipado.

No corpus saussuriano, aquilo que concerne à semiologia deveria, nessa perspectiva em particular, chamar a atenção: as poucas linhas atribuídas ao tema no CLG (uma parte ínfima do que encontramos nas notas manuscritas, nos cursos, nas Lendas germânicas... durante tanto tempo inacessíveis) terão uma influência (tardia, vale observar) sem medida comum com sua importância quantitativa. É que o projeto semiológico saussuriano tinha um valor projetivo, próximo de uma "utopia" de pensamento: a "ideia" de uma disciplina suscetível de se encarregar da diversidade das produções simbólicas humanas que, ao mesmo tempo, fundaria a linguística e dela tiraria o essencial de seus recursos ${ }^{6}$. Foi apenas retrospectivamente que essa "utopia" se tornou um "programa" científico a ser realizado, e é somente depois de 1945 que esse programa tomará corpo, quando o Curso adquiriu o status de uma "herança" no sentido que demos a esse termo anteriormente a partir, em especial, do que M. Foucault, na Arqueologia do saber, chama de "domínio de memória" de uma disciplina:

Trata-se de enunciados que não são mais nem admitidos nem discutidos, que não definem mais, por consequência, nem um corpo de verdades, nem um domínio de

\footnotetext{
6 A utopia política, sabemos, se distingue radicalmente do "programa político reformador" na medida em que ela se subtrai por princípio (e não por acidente ou impotência anedótica) da prova do "realizável". Trata-se de um artefato de pensamento cujo valor estritamente crítico e projetivo serve para se orientar no presente que ela faz aparecer como a realização de um, entre uma infinidade de possíveis ( $c$ f. por exemplo, E. Bloch, O espirito de utopia). A ideia de semiologia saussuriana vê nessa utopia a possibilidade de uma reforma das ciências humanas da linguagem produzindo uma nova matriz disciplinar.
} 
validade, mas, em relação aos quais se estabelecem relações de filiação, de gênese, de transformação, de continuidade e de descontinuidade histórica (FOUCAULT, 1969, p. 78).

Mas onde então situar Genebra, a filologia dos textos saussurianos, o inventário do patrimônio nesse dispositivo? Sem dúvida, em parte - último anacronismo - no efeito de retorno da valorização retrospectiva da origem que apenas se deu depois de 1945. Dito de outro modo, a filologia saussuriana continua o trabalho de Bally e Sechehaye tanto quanto ela o corrige, construindo, sempre retrospectivamente, a "literalidade" de um texto segundo diferentes regimes de historicidade a cada vez mais paradoxais.

O que dizer, para concluir, da distância relativa Genebra-Paris? Como se pode ver, estamos do lado da história, contra a geografia, essa "disciplina-cuco" que faz sempre seu ninho no ninho dos outros e que exagera a importância dos lugares com vistas a parar o tempo:

\begin{abstract}
A hagiografia se caracteriza por uma predominância das precisões de lugares sobre as precisões de tempo. Do mesmo modo, ela se distingue também da biografia. Ela obedece à lei da manifestação, que caracteriza esse gênero essencialmente "teofânico": as descontinuidades do tempo são esmagadas pela permanência daquilo que é o começo, o fim e o fundamento. A bistória do Santo se traduz em percursos de lugares e em mudança de cenários; eles determinam o espaço de uma "constante" (DE CERTEAU, 1997, grifo de Christian Puech).
\end{abstract}

As descobertas ligadas às fontes não superarão o "saussurismo": elas fazem parte dele; e a ideia de destino é a menos histórica que há.

\title{
Referências
}

AARSLEFF, H. Bréal, la sémantique et Saussure. Histoire, Epistémologie, Langage, v. 3, fascículo 2. Paris: Presses Universitaires de Vincennes, 1981.

AMACKER, R. L'influence de F. de Saussure et la linguistique d'inspiration saussurienne en Suisse, 1940-1970. Cahiers Ferdinand de Saussure, v. 30. Genève: Droz, 1976.

AMSTERDAMSKA, O. Schools of Thought: the development of Linguistics from Bopp to Saussure. La Haye: Mouton, 1987.

AUROUX, S. Deux hypothèses sur les sources de la conception saussurienne de la valeur linguistique. Tralili, v. XIII, nº 1, 1985.

BOUQUET, S. Introduction à la lecture de Saussure. Paris: Payot, 1997.

CHISS, J. L.; PUECH, C. Fondations de la linguistique. Etudes d'histoire et d'épistémologie. Bruxelles: Duculot, 1987. 
DE CERTEAU, M. Hagiographie! Dictionnaire des genres et notions littéraires. Paris: Albin Michel, 1997.

DERRIDA, J. De la grammatologie. Paris: Editions de Minuit, 1968.

FOUCAULT, M. L’archéologie du savoir. Paris: Gallimard, 1967.

FREI, H. La linguistique saussurienne à Genève depuis 1939. Acta Linguistica, v. 5, 1945.

GODEL, R. L'école saussurienne de Genève. Cahiers Ferdinand de Saussure, v. 38. Genève: Droz, 1984 [1961].

HENRY, V. Antinomies linguistiques. Paris: Alcan, 1896.

KOERNER, E. F. K. Ferdinand de Saussure: origin and development of his linguistics thought in western studies of language. Braunschweig: F. Vieweg, 1973.

Meillet, Saussure et la linguistique générale. Histoire, Epistémologie, Langage, v. 10, $\mathrm{n}^{\circ}$ 2. Paris: Presses Universitaires de Vincennes, 1988.

LEPSCHY, G. C. Saussure et gli Spiriti. In: AMACKER et al. Studi saussuriani per Robert Godel. Bologne: Il Mulino, 1974.

NERLICH, B. La pragmatique. Tradition ou révolution dans l'histoire de la linguistique française. Frankfurt: Peter Lang, 1986.

NORMAND, C. et al. Avant Saussure: choix de textes. Bruxelles: Editions Complexe, 1978.

PARIENTE, J. C. Essais sur le langage. Paris: Editions de Minuit, 1969.

PUECH, C. Sémiologie et histoire des théories du langage. Langages, v. 107, Paris, 1992.

SAUSSURE, F. de. Cours de linguistique générale. Paris: Payot, 1975.

SECHEHAYE, A. L'école de linguistique générale. I. G. F. v. 44, Genève, 1927. Les trois linguistiques saussuriennes. Vox Romanica, v. 5, 1940.

SERIOT, P. Structure et totalité. Paris: Presses Universitaires de France, 1999.

SIMONE, R. The Language-user in Saussure (and after). In: FORMIGARI, L.; GAMBARARA, D. (Org.). Historical Roots of Linguistic Theories. Amsterdam; Philadelphia, John Benjamins Publishing Company, 1995.

WUNDERLI. Problèmes et résultats de la recherche saussurienne. Cahiers Ferdinand de Saussure, v. 36. Genève: Droz, 1982. 